\title{
The Influence of Size and Chemical Composition of Silver and Gold Nanoparticles on in vivo Toxicity with Potential Applications to Central Nervous System Diseases
}

This article was published in the following Dove Press journal:

International Journal of Nanomedicine

\author{
Daniela F Báez ${ }^{1-3, *}$ \\ Eduardo Gallardo-Toledo 1,2,* \\ María Paz Oyarzún 1,2 \\ Eyleen Araya ${ }^{2,4}$ \\ Marcelo J Kogan (iD) ${ }^{1,2}$ \\ 'Department of Pharmacological and \\ Toxicological Chemistry, Faculty of \\ Chemical and Pharmaceutical Sciences, \\ University of Chile, Santiago, Chile; \\ ${ }^{2}$ Advanced Center for Chronic Diseases \\ (ACCDIS), Santiago, Chile; ${ }^{3}$ Redox \\ Process Research Center, CIPRex, \\ Faculty of Chemical and Pharmaceutical \\ Sciences, University of Chile, Santiago, \\ Chile; ${ }^{4}$ Departamento de Ciencias \\ Quimicas, Facultad de Ciencias Exactas, \\ Universidad Andres Bello, Santiago, Chile \\ *These authors contributed equally to \\ this work
}

\begin{abstract}
The physicochemical and optical properties of silver nanoparticles (SNPs) and gold nanoparticles (GNPs) have allowed them to be employed for various biomedical applications, including delivery, therapy, imaging, and as theranostic agents. However, since they are foreign body systems, they are usually redistributed and accumulated in some vital organs, which can produce toxic effects; therefore, this a crucial issue that should be considered for potential clinical trials. This review aimed to summarize the reports from the past ten years that have used SNPs and GNPs for in vivo studies on the diagnosis and treatment of brain diseases and those related to the central nervous system, emphasizing their toxicity as a crucial topic address. The article focuses on the effect of the nanoparticle's size and chemical composition as relevant parameters for in vivo toxicity. At the beginning of this review, the general toxicity and distribution studies are discussed separately for SNPs and GNPs. Subsequently, this manuscript analyzes the principal applications of both kinds of nanoparticles for glioma, neurodegenerative, and other brain diseases, and discusses the advances in clinical trials. Finally, we analyze research prospects towards clinical applications for both types of metallic nanoparticles.
\end{abstract}

Keywords: silver nanoparticles, gold nanoparticles, brain diseases, central nervous system, toxicity, in vivo applications

\section{Introduction}

Nanoscale particles have been intensively studied for a wide range of in vitro and in vivo biomedical applications, such as diagnosis (sensing), therapy, drug delivery, and imaging for different diseases, due to their unique physicochemical properties, such as small size, large surface area to volume ratio, high stability, carrier capacity, and optical properties. ${ }^{1,2}$ Among the different nanoparticles used for biomedicine, silver nanoparticles (SNPs) and gold nanoparticles (GNPs) ${ }^{1-3}$ have stood out from the rest, since they also show better performance of localized surface plasmon resonance (LSPR). This LSPR arises from a coherent oscillation of the surface conduction electrons excited by electromagnetic radiation of a wavelength much smaller than that of the nanoparticles. ${ }^{4,5}$ This phenomenon is absent in small nanoparticles $(\mathrm{d}<2.0 \mathrm{~nm})$ and in bulk materials and is sensitive to changes in size, shape, ${ }^{3}$ surface functionalization, solvent, core charge, and temperature. ${ }^{1,3,6,7}$ As shown in Figure 1, the increase in SNPs and GNPs size shifts the LSPR to a greater wavelength. ${ }^{8-11}$
Correspondence: Eyleen Araya

Departamento de Ciencias Quimicas, Facultad de Ciencias Exactas, Universidad Andres Bello, Santiago, 8370035, Chile

Email eyleen.araya@unab.cl

Marcelo J Kogan

Departamento de Química Farmacológica y Toxicológica, Facultad de Ciencias Químicas y Farmacéuticas, Universidad de Chile, Santiago, 8380494, Chile

Email mkogan@ciq.uchile.cl
International Journal of Nanomedicine 2021:16 2187-2201

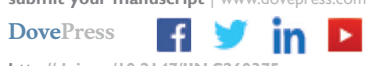

(c) (i) (5) 2021 Báez et al. This work is published and licensed by Dove Medical Press Limited. The full terms of this license are available at https://www.dovepress.com/terms.php c. you hereby accept the Terms. Non-commercial uses of the work are permitted without any further permission from Dove Medical Press
permission for commercial use of this work, please see paragraphs 4.2 and 5 of our Terms (https://www.dovepress.com/terms php). 
SNPs and GNPs of different sizes and morphologies exhibit high efficiency in the LSPR. ${ }^{12,13}$ However, despite the wide use of SNPs, there are concerns regarding their adverse effects on human health. ${ }^{14}$ On the other hand, GNPs possess some advantages, such as easy, reproducible synthesis and optoelectronic properties, which are related to GNPs size and shape, and the surface's functionalization/stabilization with a wide range of molecules (polymers, proteins, and oligonucleotides); therefore, GNPs have been the main nanoparticle studied for biomedical applications. ${ }^{15-18}$

Among the different biomedical applications of SNPs and GNPs, our particular interest was to review articles where these nanoparticles were used for in vivo diagnosis and treatment of diseases related to the central nervous system (CNS). Even though a diverse range of nanoparticles are able reach the brain after systemic administration, most of them have a limited delivery to the CNS due to the blood-brain barrier (BBB).$^{19}$ The BBB is a defensive, highly selective, and low permeable barrier that isolates the CNS, protecting and generating a stable environment for neurons. The use of transport mechanisms present in the BBB allows the passage of essential molecules for the brain's correct function, and has been explored to deliver nanoparticles to the CNS. ${ }^{20-22}$

Nevertheless, a very crucial aspect to consider is the nanoparticle's potential neurotoxic effect, which must be addressed for their potential clinical use. ${ }^{23,24}$ Physicochemical characteristics such as size, shape, chemical composition, surface charge, and aggregation state may affect the toxicological profile of the nanoparticles ${ }^{25}$ and thus, condition their biomedical applications. ${ }^{26}$ Several studies have indicated that small nanoparticles
A
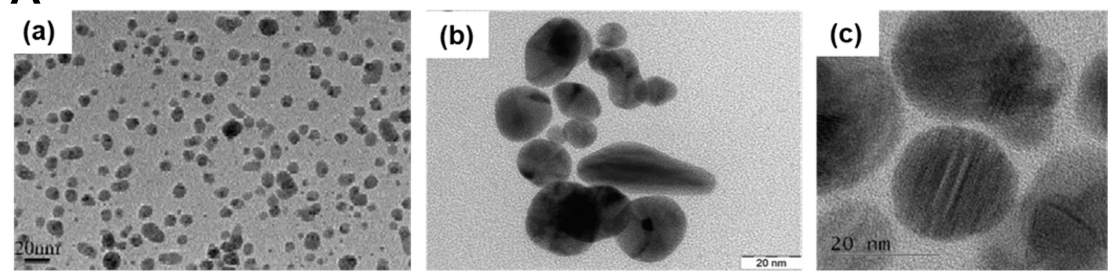

C

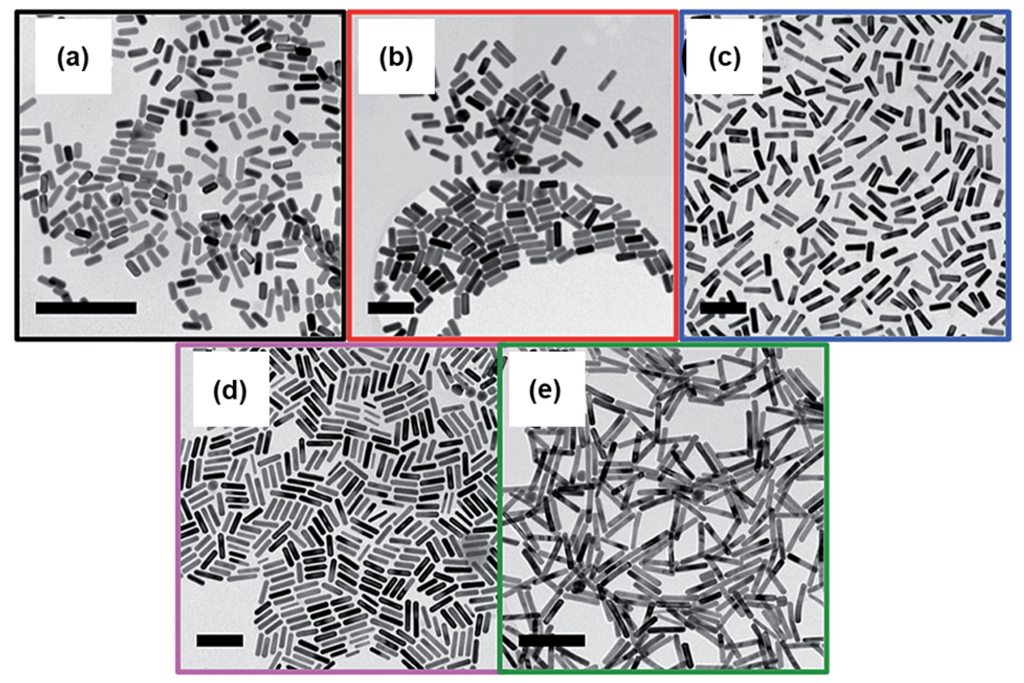

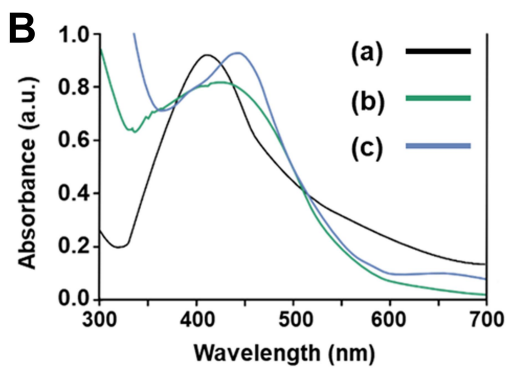

D

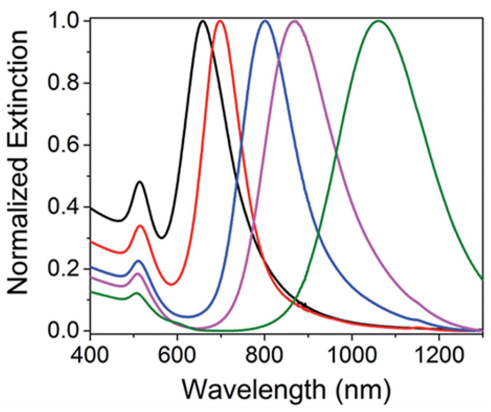

Figure I Effects of size on the plasmon band. (A) TEM images of SNPs of 10 (a), 20 (b), and 20-30 (c) nm. (B) UV-Vis spectra of the SNPs shown in (A). (C) TEM images of GNPs with aspect ratios of 2.4 (a), 2.7 (b), 3.6 (c), 4.4 (d), and 6.1 (e), scale bars are I $50 \mathrm{~nm}$. (D) UV-Vis spectra of the GNPs shown in (C). TEM images with their respective spectra were adapted with permission from: (A)(a) Adapted with permission from Liu P, Huang Z, Chen Z, et al. Silver nanoparticles: a novelradiation sensitizer for glioma? Nanoscale. 2013;5(23): I 829. Copyright 2013, Royal Society of Chemistry ${ }^{8}$; (A)(b) Adapted from Nakkala JR, Mata R, Raja K, Khub Chandra V, Sadras SR. Green synthesized silver nanoparticles: catalytic dye degradation,in vitro anticancer activity and in vivo toxicity in rats. Mat SciEng C. 20I8;9I:372-38I.Copyright 20I8, with permission from Elsevier.; (A)(c) Adapted from Khan I, Bahuguna A, Krishnan M, et al. The effect of biogenicmanufactured silver nanoparticles on human endothelial cells andzebrafish model. Sci Total Environ. 2019;679:365-377. Copyright 2019, with permission from Elsevier ${ }^{10}$; and (C)(a-e) Adapted with permission from Hinman JG, Stork AJ, Varnell JA, Gewirth AA, Murphy CJ. Seedmediated growth of gold nanorods: towards nanorodmatryoshkas. Faraday Discuss. 2016;191:9-33. Copyright 2016, Royal Society of Chemistry" respectively. 
can pass through the BBB; however, very small nanoparticles are vulnerable to renal and kidney excretion and clearance from target tissues. On the contrary, nanoparticles of bigger sizes $(\geq 20 \mathrm{~nm})$ can pass through the BBB, but larger nanoparticles $(>200 \mathrm{~nm})$ can be susceptible to uptake by other organs. ${ }^{26}$ Moreover, many studies have reported that even though the percentage of injected doses that reach the brain is relatively low, a high accumulation occurs in other vital organs, such as the liver and spleen. ${ }^{6,7,27-29}$ This nanoparticle biodistribution and accumulation behavior may lead to an undesirable exposure to metal nanoparticles with potential toxic effects.

Regarding clinical trials related to applications of SNPs and GNPs for the treatment of central nervous system diseases, it is important to point out that, to date, no clinical studies have been conducted for CNS-related applications. Only general controlled clinical trials have been conducted for SNPs and GNPs, including the efficacy of SNPs as anti-cariogenic agents, ${ }^{30}$ cariostatic efficacy ${ }^{31}$ to prevent plaque accumulation, ${ }^{32}$ and in wound healing after anorectal surgery in human patients. ${ }^{33}$ In the case of GNPs, most of the trials have focused on the treatment and diagnosis of cancer using different shapes and coats. ${ }^{34-39}$ Furthermore, GNP-based nanosystems have been clinically studied to treat and diagnose other diseases, such as atherosclerosis, ${ }^{40}$ demyelinating neuromyelitis optica, ${ }^{18}$ and pulmonary arterial hypertension. ${ }^{41}$

This review presents a comprehensive overview of in vivo studies that have used SNPs and GNPs for biodistribution and toxicity purposes during the last ten years. Emphasis is made on the size and chemical composition of these nanoparticles (also referred to as functionalization in this review), as the factors that may cause neurotoxicity. Of note, we excluded the articles that described in vitro studies, but these have been recently revised in Sawicki et $\mathrm{al}^{42}$ and Ferdous et al. ${ }^{43}$ Finally, we address the current clinical trials reported for both kinds of nanoparticles and discuss the challenges to be addressed and prospects to advance towards effective clinical use of SNPs and GNPs for nanomedicine.

\section{General Toxicity and Distribution Studies}

The size and functionalization of SNPs and GNPs change their physicochemical characteristics, affect their distribution and accumulation and thus, their toxicity. Related to the in vivo behavior, an essential step is to study how these factors affect the toxicity of SNPs and GNPs. Here, we refer to studies that elaborately evaluated nanoparticle biodistribution, accumulation, and clearance in animals, with a special interest in the CNS.

\section{Silver Nanoparticles \\ Size}

Exposure to SNPs and their persistence in the body can trigger undesirable effects. ${ }^{44}$ However, it is still controversial if toxicity is associated with the nanoparticle itself or with the release of silver ions. ${ }^{45}$ In this sense, DąbrowskaBouta et $\mathrm{al}^{46}$ assessed prolonged and low-dose exposure to SNPs $\left(10 \mathrm{~nm}\right.$, citrate-stabilized) or ionic silver $\left(\mathrm{Ag}^{+}\right)$in male Wistar rats. Slight differences in behavior were found, but rats treated with SNPs increased their body weight and temperature, whereas after $\mathrm{Ag}^{+}$exposure, animals presented a weak depressive effect and hyperalgesia. Pathological changes in myelin were also observed in brain tissues from $\mathrm{Ag}^{+}$and SNPs-treated groups, compared to controls, and the levels of all examined proteins significantly decreased in the rats treated with $\mathrm{Ag}^{+}$and SNPs, suggesting that both treatments produce a neurotoxic effect. Hadrup et $\mathrm{al}^{24}$ carried out a similar study, but compared the neurotoxic effects of $14 \mathrm{~nm}$ SNPs coated with polyvinylpyrrolidone (PVP) and ionic silver $\left(\mathrm{Ag}^{+}\right.$, the form of silver acetate). SNPs, and a filtered fraction (containing ionic silver, $12 \mathrm{kDa}$ ), showed equal toxicity, whereas ionic silver was toxic at doses two or tenfold lower than those of SNPs. Female Wistar rats orally treated with SNPs-PVP or $\mathrm{Ag}^{+}$for 28 days did not show general appearance or behavioral changes, but presented alterations in neurotransmitter levels. The authors found a dose-response effect on neurotransmitter levels at the highest SNP concentration and the equimolar concentration for $\mathrm{Ag}^{+}$in the treatment. Both SNPs and $\mathrm{Ag}^{+}$also increased 5-hydroxytryptamine, noradrenaline and dopamine levels. ${ }^{47,48}$ Moreover, the addition of SNPs to PC12 cells led to alterations in the mRNA levels of dopaminerelated genes, ${ }^{49}$ confirming that SNPs or ionic silver induce disturbances of neuronal cell differentiation and concomitant ability to produce dopamine. The results suggest that SNPs and ionic silver exert similar neurotoxic effects.

Soria et al investigated the toxic effects of commercial $10 \mathrm{~nm}$ SNPs on wild type and transgenic Caenorhabditis elegans (C. elegans) strains expressing two prototypic amyloidogenic proteins: b2-microglobulin and $A \beta_{3-42}$ peptide. The toxicity of SNPs could be detected in C. elegans 
at lower concentrations than in in-vitro studies. In the N2 wild type $C$. elegans, the exposure to a range of SNP concentrations significantly affected the worm's body bends in a dose-dependent manner. In the absence of nanoparticles, both transgenic strains exhibited a significant defect in their locomotory function, compared to the ancestral nematodes, but SNPs severely worsened their motility. A dose-dependency was also observed with the highest concentration tested $\left(5.2 \mu \mathrm{g} / \mathrm{cm}^{2}\right)$, which reduced body bends by almost $50 \%$ in the transgenic strains; $50 \%$ in the strains expressing b2-m, and $30 \%$ in those expressing the A $\beta$ peptide (versus $20 \%$ in N2 wild type $C$. elegans). ${ }^{50}$

The aforementioned studies suggest that small silver nanoparticles ranging from $10-20 \mathrm{~nm}$ possess in vivo toxicity effects, probably due to the induced production and release of silver ions from the nanoparticle's surface.

\section{Functionalization}

Surface modification of SNPs has been carried out for targeting and to improve their colloidal stability. Some studies, such as that of Khan et al, ${ }^{10}$ have leaned towards a green synthesis of nanoparticles by studying the in vivo toxicity of Rumex acetosa SNPs of 20 to $30 \mathrm{~nm}$ (SNPs-RU) in a zebrafish model. Zebrafish embryos orally treated with SNPs-RU showed embryonic head and pericardial malformations, yolk sac edema, and a bent tail. Increased exposure to SNPs-RU also increased mortality and produced severe toxicity in a dose-dependent manner. SNPs-RU at 50 and $100 \mu \mathrm{g} / \mathrm{mL}$ concentrations produced pericardial edema and bent tail formation, indicating that SNPs-RU mediate apoptosis in a dose-dependent manner.

The previous report described an oral administration route. However, other vias, such as intravenous (IV) or intranasal (IN), may lead to distinct accumulation, retention, and elimination profiles and therefore, different toxic outcomes. Chrastina et $\mathrm{al}^{28}$ developed radiolabeled $12 \mathrm{~nm}$ SNPs stabilized with polyvinylpyrrolidone (SNPs-PVP) and iodine-125 for in vivo tissue uptake tracking after IV administration in Balb/c mice. Biodistribution analysis revealed the highest uptake in the liver and spleen (24 and 41\% ID/g, respectively), and minimal brain uptake $(<0.1 \% \mathrm{ID} / \mathrm{g})$. Even though the authors indicated that SNPs strongly tend to produce hepatotoxic effects due to their higher accumulation in the liver, long-term exposure may trigger higher brain accumulation and retention, as described by Antsiferova et $\mathrm{al}^{27}$ who used a similar, but larger $(34 \mathrm{~nm})$ nanosystem. Biodistribution, accumulation, and excretion after oral administration of SNPs-PVP in SHK mice and the ability of SNPs to penetrate the brain after a single- or multiple-administration (100 $\mu \mathrm{g}$ of SNPs) was reported. The highest concentrations were observed in the liver and blood in one-time exposure experiments (Figure 2Aa). However, redistribution was observed at two months, with the highest silver concentration in the brain and liver (Figure 2Ab). Even though the silver concentration was reduced in all organs after one month without treatment (Figure 2Ac), a shallow level of SNPs excretion from mouse brains (only $6 \%$ per month) was detected, compared to that observed in blood and the liver (about 80\%), which may be due to accumulation of SNPs. ${ }^{27}$ Similar results were described by Wen et $\mathrm{al}^{51}$ who studied intranasal instillation of SNPs-PVP $(26 \mathrm{~nm})$ or $\mathrm{Ag}^{+}$in neonatal SpragueDawley rats treated during a short-term study (4 weeks) or a long-term study (12 weeks +4 weeks of recovery). No physiological alterations or behavioral changes were observed in rats treated with SNPs or $\mathrm{Ag}^{+}$at lower concentrations $\left(0.1 \mathrm{mg} \mathrm{kg}^{-1}\right.$ day $\left.^{-1}\right)$. However, at $1 \mathrm{mg} \mathrm{Kg}^{-1} \mathrm{day}^{-1}, \mathrm{Ag}^{+}$exposure decreased body weight gain and caused $18.2 \%$ of mortality. The in vivo distribution and retention of SNPs or $\mathrm{Ag}^{+}$were evaluated by measuring total silver concentrations, which were found predominantly in the liver (Figure $2 \mathrm{Ba}$ ) for both $\mathrm{Ag}^{+}$and SNP treatments after four weeks of exposure, similar to previous reports. ${ }^{52}$ Interestingly, in the $\mathrm{Ag}^{+}$group, the second-highest silver level was detected in brain samples. The silver distribution analysis in specific brain regions, including the cortex, cerebellum, hippocampus, medulla, and olfactory bulb, is shown in Figure $2 \mathrm{Bb}$, which depicts that all five regions contained equally high silver content in the $\mathrm{Ag}^{+}$ and SNP groups. The tissue distribution profile varied distinctly after 12-weeks of exposure. The highest silver content was observed in brain tissue for both $\mathrm{Ag}^{+}$and SNPs, with a significant decrease in liver silver concentrations (Figure 2Bc). Finally, the silver retention study revealed that the elimination ratios of silver in serum and liver after 1 - and 4-weeks of recovery were approximately higher than $60 \%$ for both treatments. However, and similarly to the study by Antsiferova et al, ${ }^{27}$ silver concentrations in the brain remained unchanged or slightly elevated.

Therefore, despite the incorporation of molecules on the surface of 10 to $30 \mathrm{~nm}$ SNPs, the reported studies 
A

(a)

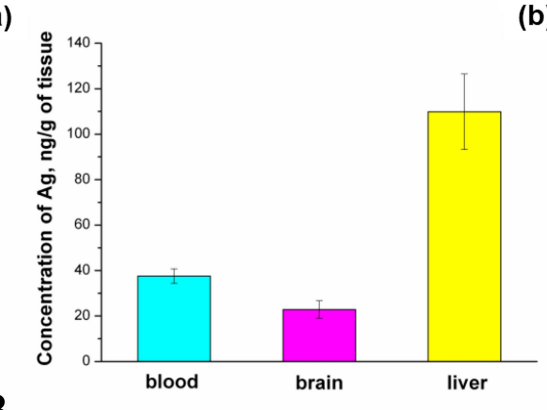

B

(a)

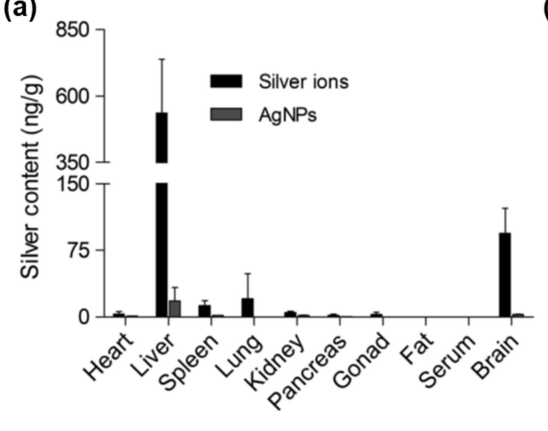

(b)

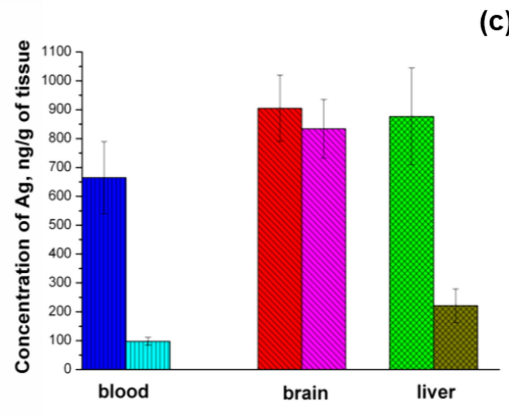

(c) 。

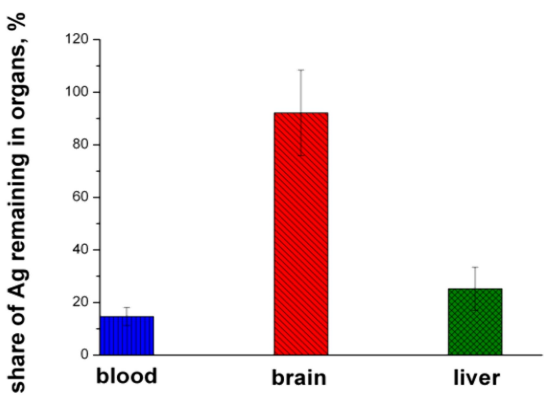

(b)

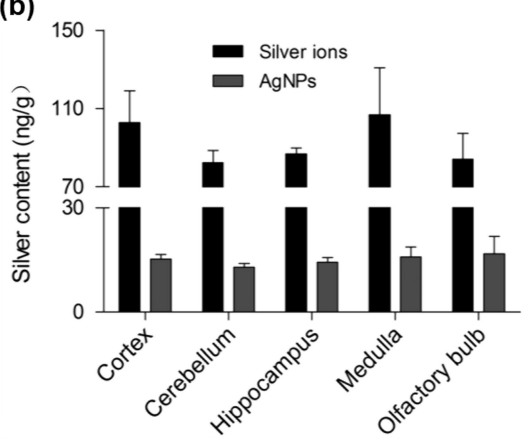

(c)

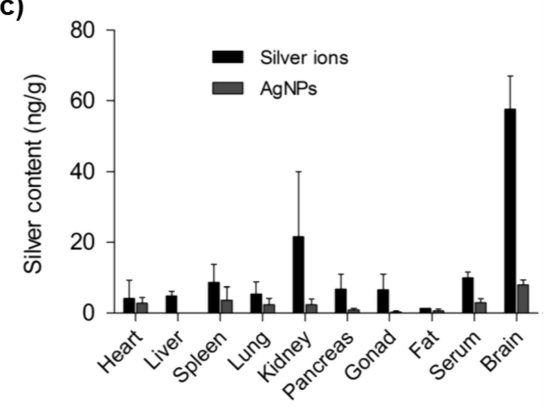

Figure 2 Biodistribution and toxicity of SNPs. (A) Silver concentrations in different organs (a) after one-time exposure to SNPs of size 34 nm, stabilized with PVP (b) after long-time exposure, (c) Fractions of silver remaining in mouse organs after I month of washing up. Adapted with permission from. Antsiferova A, Buzulukov $\mathrm{Y}$, Demin $\mathrm{V}$, Kashkarov P,Kovalchuk M, Petritskaya E. Extremely low level of Ag nanoparticle excretion from mice brain in in vivo experiments. IOPConference Series. 20I5;98:0I 2003. Creative Commons Attribution 3.0 licence (https://creativecommons.org/licenses/by/3.0/). ${ }^{27}$ (B) Silver concentrations in main rat organs with daily intranasal administration of silver ions and SNPs of size $26 \mathrm{~nm}$, at a dosage of $0.1 \mathrm{mg} \mathrm{kg}^{-1}$ body weight day I (n= 4). (a) 4-week exposure (b) Silver distribution in different rat brain regions after 4-week exposure. (c) 12-week exposure. Adapted with permission from Wen R, Yang X, Hu L, Sun C, Zhou Q, Jiang G. Brain-targeteddistribution and high retention of silver by chronic intranasalinstillation of silver nanoparticles and ions in Sprague-Dawley rats. J Appl Toxicol. 2016;36(3):445-453. Copyright 20I6 John Wiley and Sons. ${ }^{5}$

revealed the presence of toxic effects under the conditions studied, ${ }^{10,49}$ suggesting that SNP hazard might be associated with the release of ionic silver from the nanoparticle's surface and its action. As described, SNPs exhibit a longer half-life in the brain than in other organs. Given this tendency, SNPs and the related dissolved ions exert considerable neurotoxic effects, ${ }^{53}$ leading to an inflammatory response and oxidative stress, of which, the latter has been reported as one of the most important toxicity mechanisms related to silver exposure. $^{54-56}$

\section{Gold Nanoparticles \\ Size}

Nanoparticle size may significantly influence the toxicological profile of gold nanosystems. Lee et $\mathrm{al}^{20}$ determined the cytotoxicity of 5 and $100 \mathrm{~nm}$ GNPs in human neural precursor cells (NPCs) and Sprague Dawley rats via unilateral injection, stereotactically administered in the right cerebral cortex. The dose-dependency study on NPCs showed that $5 \mathrm{~nm}$ GNPs were more cytotoxic than 100 $\mathrm{nm}$ GNPs, reducing cell viability by up to $50 \%$. Toxicity in the brain was determined in vivo by measuring nestin, whose expression is related to CNS injury. $5 \mathrm{~nm}$ GNPs showed higher nestin expression than $100 \mathrm{~nm}$ GNPs in immunoreactive cells, confirming that smaller GNPs were more toxic. On the other hand, other reports have demonstrated that the use of GNPs, with sizes ranging from 2 to $50 \mathrm{~nm}$, does not produce significant neurotoxic effects. ${ }^{6,57}$ Naz et $\mathrm{al}^{6}$ reported a long-term in vivo study (90 days) of biokinetics, redistribution, and urinary excretion of $2 \mathrm{~nm}$ amine-terminated, citrate-capped $5 \mathrm{~nm}$ and $10 \mathrm{~nm}$ GNPs, administered by single IV injection in swiss albino mice at the dose of $1250 \mu \mathrm{g} / \mathrm{Kg}$. The retention of GNPs in vital organs, such as the liver, spleen, lungs, heart, kidney, and brain, was estimated at different time points using inductively-coupled plasma atomic emission spectroscopy (ICPAES). The maximum amount of GNPs found in the brain was $2.0,2.2,2.3 \mu \mathrm{g} / \mathrm{g}$ for 2,5 , and $10 \mathrm{~nm}$ GNPs, respectively, and corresponded to lower concentrations than 
those found in other organs. The concentration of GNPs gradually decreased 1-day post-injection, and low concentrations were detected after 30 days. Brain tissue images showed occasional gold clusters in neurons and glial cells and confirmed very low sequestration of GNPs in the brain parenchyma. Moreover, the long-term study showed no effects of 2, 5, and $10 \mathrm{~nm}$ GNPs on mortality or abnormality of behavior, weight, necrosis, or fibrosis, compared with normal control mice. The authors indicated that ultrafine GNPs did not produce systemic toxicity and may be considered safe for drug delivery.
Moreover, $50 \mathrm{~nm}$ GNPs obtained from phytosynthesis showed to be biocompatible. ${ }^{58}$ In this study, Wistar rats were intravenously administered with GNPs every alternate day for 28 days. Brain sections of animals showed a normal cerebellum, no alterations in cerebrospinal fluid, and the brain tissue evidenced normal axons. No detectable abnormalities in the experimental animals were found, compared to the control group, and no significant differences were noticed in body weight or hematological and biochemical parameters. Rocha et al used $50 \mathrm{~nm}$ GNPs, but capped with citrate, to evaluate the daily activity and survival rates during two months, as

\section{A}

(a)

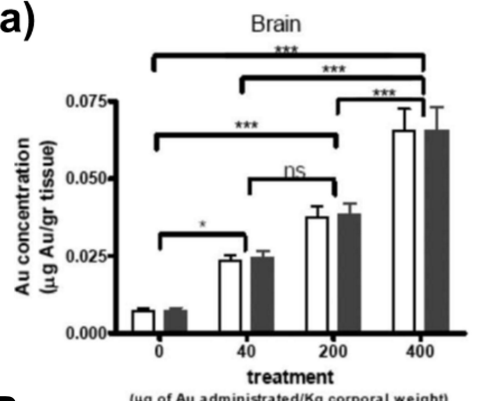

B

(a)

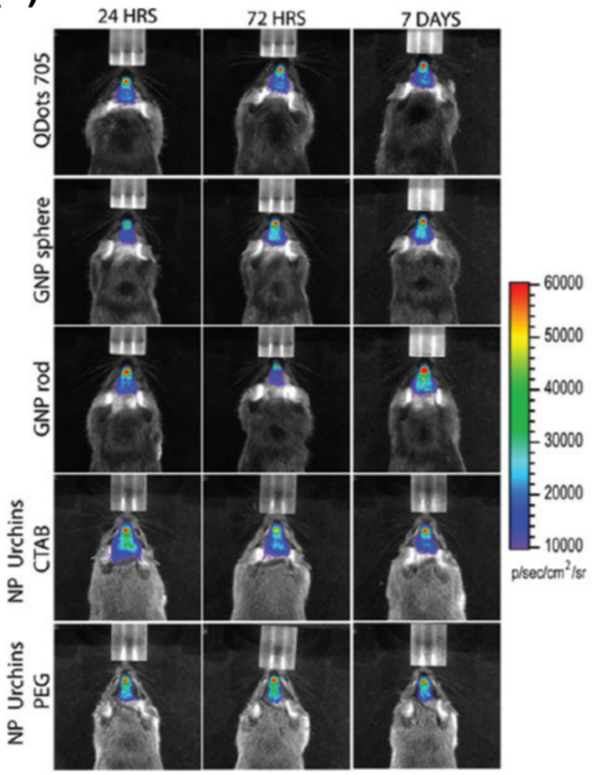

(b)
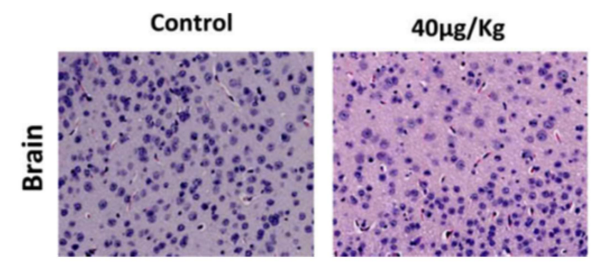

$200 \mu \mathrm{g} / \mathrm{Kg}$

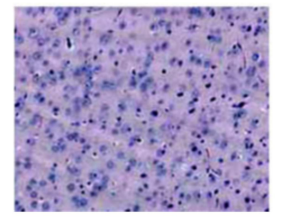

$400 \mu \mathrm{g} / \mathrm{Kg}$

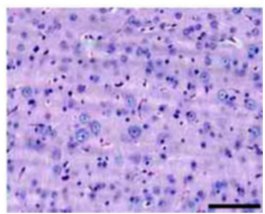

(b)

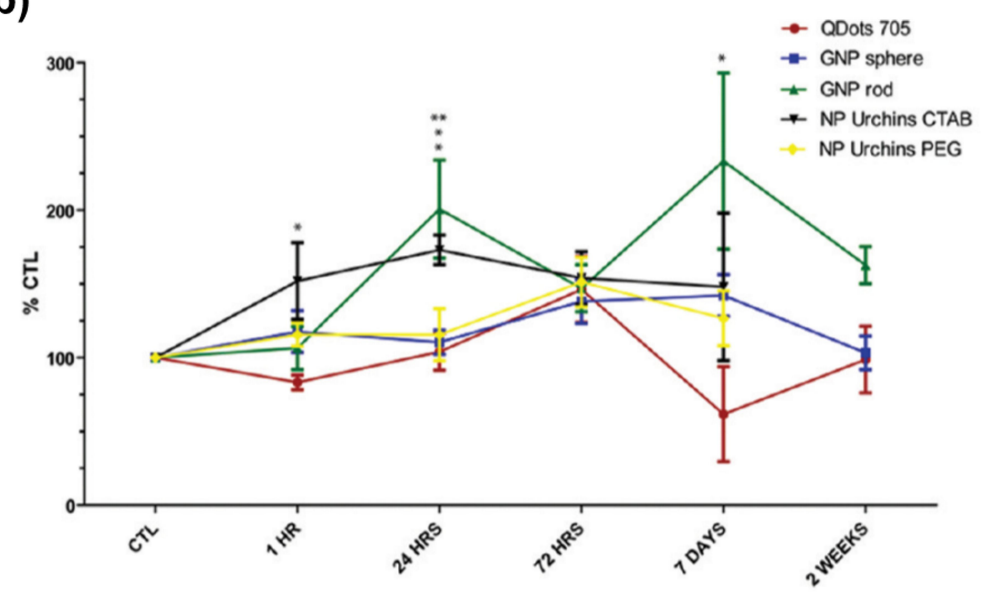

Figure 3 Distribution and toxicity of GNPs in the CNS. (A) Gold accumulation in the brain after intraperitoneal injection of GNPs (40, 200 , and $400 \mu \mathrm{gg} / \mathrm{kg}$ ) for 8 consecutive days. (a) Gold accumulation was analyzed by GF-AAS (white bar) and ICP-MS (black bar). Bars represent mean \pm standard error; data were analyzed by ANOVA with Bonferroni's post-test; ns: no significant difference, ${ }^{*} p<0.05$, ${ }^{* * *} p<0.00$ I. (b) Histological analysis of the brain after treatment with GNPs to evaluate morphology and cellular damage. Tissues were stained with hematoxylin/eosin. Size of the bar corresponds to $75 \mu \mathrm{m}$. Adapted form Lasagna-Reeves C, Gonzalez-Romero D, Barria MA, et al. Bioaccumulation and toxicity of gold nanoparticles after repeatedadministration in mice. Biochem Biophys Res Commun. 20I0;393(4):649-655. Copyright (20I0), with permission from Elsevier. ${ }^{59}$ (B) In vivo bioluminescence imaging of microglia in transgenic mice after intranasal administration of GNPs. (a) Representative pseudocolor bioluminescence images ( 24 h, 72 h, 7 days, and 14 days) are shown for Quantum Dots 705, PEGylated gold spheres, rods, and urchins, and urchins capped with CTAB. At right, quantification scales of the total photon emission signal (photon $/ \mathrm{s} / \mathrm{cm}^{2} / \mathrm{sr}$ ). (b) Time course of the change in bioluminescence signal intensity in mice. Note a biphasic activation of microglia caused by rod GNPs, and a small, but significant microglia response to gold spheres. Mean values and standard error of the means from four animals per group per time point are shown. Significant differences: ${ }^{*} p<0.05 ; * *<0.01$. Adapted with permission from Hutter E, Boridy S, Labrecque S, et al. Microglial response togold nanoparticles. ACS Nano. 2010;4(5):2595-2606. Copyright (C 2010, American Chemical Society. ${ }^{65}$; Images were with permission from Refs. 
parameters of neurotoxicity in cockroaches (Blaberus discoidalis). ${ }^{57}$ GNPs affected insect behavior, but had no major impact on their life expectancy, which may be attributed to the encapsulation of GNPs inside the insect's brain (day 17).

Lasagna-Reeves et al evaluated the bioaccumulation and sub-acute toxicity of $12 \mathrm{~nm}$ GNPs in C57/BL6 mice. ${ }^{59}$ Mice received daily intraperitoneal (IP) injections at doses of 40, $200,400 \mu \mathrm{g} / \mathrm{kg} /$ day for 8 days. Results indicated that GNPs reached the CNS, and tissue accumulation was proportional to the administered doses (Figure 3Aa). At any of these doses, there were no alterations of behavior, animal weight, organ morphology, blood biochemistry, nor in histology examinations of the brain (Figure $3 \mathrm{Ab}$ ) and other major organs.

Another interesting study evaluated the interaction of uncoated GNPs $(40 \mathrm{~nm})$ and gold microparticles (GMPs, $637 \mathrm{~nm})$ with endothelial cell barriers. ${ }^{60}$ Neither were genotoxic, mutagenic, nor affected the daily mortality and clinical behavior of ICR mice. However, when the authors examined the extravasation of Evans Blue dye in mice treated with GNPs, blue staining was evident in the brain at 24 and $48 \mathrm{~h}$ after dosing. These results suggested that GNPs alter the components of tight endothelial junctions, addressing the double-edged-sword effect of GNPs. Further studies are needed to investigate the direct/indirect toxicity caused by the opening of endothelial tight junctions induced by GNPs.

\section{Functionalization}

The incorporation of molecules on the nanoparticle's surface may improve biocompatibility of gold-based nanosystems and increase their delivery to the CNS. In this sense, $20 \mathrm{~nm}$ citrate GNPs were functionalized with a mixture of PEG and insulin (GNPs-INS) to determine their biodistribution pharmacokinetics for 48 hours. ${ }^{19}$ GNPs-INS and control GNPs were injected into the tail vein of male BALB/c mice. Higher accumulation of GNP-INS was found in the liver and pancreas, whereas the \%ID in the brain was $0.64 \%$. Toxicological analysis revealed that the maximum injected dose (6 mg Au per mouse) had no toxic effects in vivo. Later, the same group explored the brain distribution of GNPs-INS. ${ }^{7}$ Ex vivo and in vivo CT imaging and gold quantification studies revealed that particles migrated to the cerebral cortex, cerebellum, and hippocampus, which are structures involved in neurodegenerative and neuropsychiatric disorders. The authors mentioned that GNPs-INS were cleared from the brain by $48 \mathrm{~h}$ post-injection.
Improving the delivery of GNPs to the CNS is one of the main goals for the development of treatments or diagnostic tools. However, long retention in the brain may trigger toxic effects. Spinelli et al ${ }^{61}$ studied the kinetics, distribution, and stability of Cy5.5-labeled GNPs in CD1 mice. Although GNPs showed low cytotoxicity in cultured hippocampal neurons, in vivo pharmacokinetic distribution in the brain showed particle retention up to 25 days after intravenous injection. Therefore, in order to assess the biocompatibility of these goldbased nanosystems, long-term studies should be carried out. Sousa et $\mathrm{al}^{62}$ coated $15 \mathrm{~nm}$ citrate-GNPs with polyallylamine hydrochloride (PAH), polystyrene sulfonate (PSS), and human serum albumin to study the in vivo distribution of GNPs up to 7 days. The peak concentration in the head was detected between 19 and $24 \mathrm{~h}$. GNPs were preferentially found in the hippocampus, thalamus, hypothalamus, and the cerebral cortex, brain areas of particular interest because they are related to Alzheimer's (cerebral cortex), Parkinson's (substantia nigra), and prion disease. No alteration in animal behavior was found over the complete experimental frame of 7 days.

Gold nanoclusters of about $3 \mathrm{~nm}$ have been radiolabeled with ${ }^{64} \mathrm{Cu}\left({ }^{64} \mathrm{Cu}\right.$-GNCs $)$ and complemented with the FUSIN technique to evaluate the ex-vivo spatial biodistribution in C57BL/6 mice. ${ }^{63}$ Intranasal delivery of ${ }^{64} \mathrm{Cu}-\mathrm{GNCs}$ and FUSIN to the brainstem enhanced the delivery to the brain region by 2.72 -fold, compared with intranasal administration only, and histological studies indicated that these nanoparticles did not produce tissue damage in the nose, trigeminal nerve, nor in the brain. Other radioisotopes have also been used to modify GNPs and monitor their biodistribution. ${ }^{29,64}$

Even though most in vivo studies have used spherical nanoparticles, only a few reports have explored how shape might affect brain toxicity in vivo. Hutter et al ${ }^{65}$ reported the interactions of microglia and neurons with GNPs of three different morphologies (spheres, rods, and urchins) and different coatings (PEG and CTAB). After intranasal administration of these GNPs in transgenic mice (Figure $3 \mathrm{Ba}$ ), a real-time study showed a transient up-regulation of toll-like receptor 2 (TLR-2) in the microglial cells located in the olfactory bulb (Figure 3Bb). In conjunction with the in vitro results, the study demonstrated that the morphology and surface chemistry of GNPs strongly influence microglial activation and potentially produce toxic effects.

The in vivo toxicity and biodistribution studies of SNPs and GNPs have shown on one side, that small SNPs of 10-30 $\mathrm{nm}$ generate toxicity, probably due to the release of silver ions, which trigger biochemical alterations, abnormities in behavior, and neurotoxic effects. Moreover, although the 


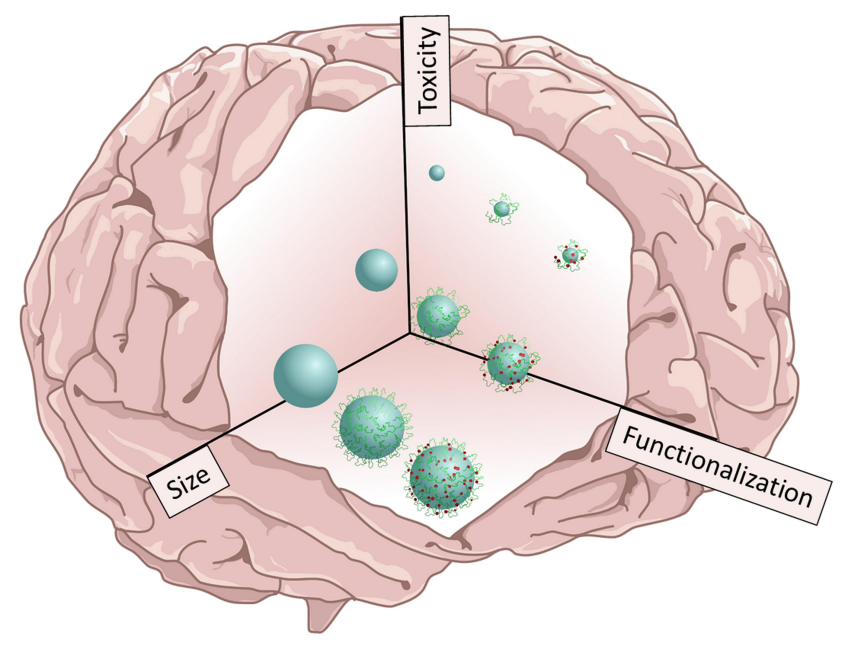

Figure 4 Effect of size and chemical composition on toxicity. Schematic illustration representing the size and chemical composition of either functionalized silver or gold nanoparticles as selected factors that produce toxicity effects in the CNS.

functionalization of SNPs diminishes their toxicity and they exhibit a more powerful radiosensitizing ability than GNPs, long-term accumulation of SNPs in the brain might be counterproductive. These results may be the cause of the limited number of articles on SNPs in the last decade.

On the other hand, the tendency to use GNPs has increased. While it is difficult to establish a correlation between size and toxicity for small GNPs ranging from 2 to $10 \mathrm{~nm}$, it is clear that larger GNPs (from 5 to $100 \mathrm{~nm}$ ) are less toxic. Moreover, the functionalization of GNPs plays a fundamental role, since it increases biocompatibility and exerts minimal or no abnormalities on animal behavior after the administration of GNP-based nanosystems. Figure 4 illustrates a general conclusion of the effect of size and functionalization on toxicity; while small and uncoated nanoparticles increase toxicity, modified nanoparticles decrease it. However, there is a marked difference between the toxicity generated by GNP and SNP, since SNPs produce silver ions and generate a long-term accumulation in the brain and therefore, higher toxic effects than GNPs.

\section{Delivery of Gold and Silver Nanoparticles to the Central Nervous System and Their Potential Biomedical Applications} Delivery of Nanoparticles to the CNS and BBB Permeability

The feasibility of developing bioapplications of SNPs and GNPs in the CNS relies on whether or not they reach the brain. One strategy to overcome the BBB is the use of ligands that recognize receptors highly expressed in the $\mathrm{BBB}$, which act as shuttles from blood circulation to the brain. ${ }^{26,66}$ The functionalization of nanoparticles with molecules such as transferrin, ${ }^{67}$ L-Dopa,${ }^{68}$ Angiopep-2, ${ }^{21}$ and HAI peptides, ${ }^{69}$ or folic acid (in the case of gliomas) ${ }^{70}$ has improved their delivery to the CNS. Another non-invasive and targeted strategy is to disrupt the BBB with ultrasound and microbubbles. Studies have demonstrated that GNPs with different sizes $^{71}$ and surface charges ${ }^{72}$ can reach the CNS after systemic administration and ultrasound and microbubbles application. Another alternative route to overcome the BBB is to change the administration route. Intranasal administration is a promising and efficient therapeutic strategy for the noninvasive treatment of various CNS diseases since the nasal cavity is described as an open gate for the transport of nanoparticles to the CNS, due to the absence of the BBB. ${ }^{73}$ However, until now, there are only a few studies that have addressed the intranasal route for the nose-to-brain delivery of nanoparticles, leaving a potential area to cover. ${ }^{65,74-77}$

\section{Glioma}

Gliomas are tumors that originate from glial cells and show a dismal prognosis. Glioblastoma multiforme (GBM) -a grade IV glioma- is the most prevalent and aggressive form. ${ }^{78}$ Table 1 summarizes the studies in which SNPs and GNPs have been used for glioma applications, where in vivo toxicity studies have been carried out. $^{79,80}$

GNPs and SNPs may be used as radiosensitization agents to improve glioma treatment. Bobyk et al compared the radiosensitization efficacy of 1.9 and $15 \mathrm{~nm}$ GNPs in Male Fischer rats. Smaller GNPs showed to be toxic, so the combined therapy that the animals received was $15 \mathrm{~nm}$ GNPs + radiation. The treated group presented a mean increase in life span of $74 \%$, in comparison to the untreated animals. ${ }^{81}$ SNPs of $114 \mathrm{~nm}$ entrapped in PLGA nanoparticles and conjugated with chlorotoxin were used for glioma treatment in a mouse model of GBM. The application of radiation allowed SNPs to inhibit tumor growth and progression and, at the same time, led to a 4 to 6 fold increase of SNP accumulation in glioma. ${ }^{82} \mathrm{Liu}$ et al demonstrated in vivo that the radiosensitizing ability of SNPs was more powerful than that of GNPs. ${ }^{83}$ Some authors have described that nanoparticles having high Zelements can generate large amounts of free radicals after activation, which amplifies and prolongs the deleterious effects of radiotherapy. ${ }^{84,85}$ Therefore, GNPs and SNPs of 
Table I Overview of Silver and Gold Nanoparticles and Their Applications for Gliomas

\begin{tabular}{|c|c|c|c|}
\hline NP (and Its Functionalization) & Mean Size (nm) & Application & Ref. \\
\hline GNPs & $\begin{array}{l}1.9 \\
15\end{array}$ & Therapeutic radiotherapy & {$[81]$} \\
\hline SNPs-PVP & 10 & Radiotherapy-imaging & [8] \\
\hline $\begin{array}{l}\text { GNPs-citrate and } \\
\text { SNPs-citrate }\end{array}$ & 15 & Radiotherapy-imaging & [83] \\
\hline GNP-PEG-FAL & 60 & Imaging-targeting and therapy & {$[93]$} \\
\hline SNP-PLGA-CTX & 114 & Sensing and therapy & {$[82]$} \\
\hline GNS-IR780-PEG & 100 & Imaging & [94] \\
\hline GNPs-U2 aptamer & 60 & Therapy & [79] \\
\hline GNP-miR-I82 & 13 & Therapy & {$[80]$} \\
\hline GNP-DOX-An & 40 & Delivery-therapy & {$[87]$} \\
\hline $\begin{array}{l}\text { GNP-AK-citrate } \\
\text { GNP-CABT-citrate }\end{array}$ & 40 & Treatment & [88] \\
\hline GNPs-A\&C-R, combined targeting with peptide R8-RGD & 41 & Treatment & [89] \\
\hline GNP- ${ }^{|3|}$ I-PENPs-CTX & $\begin{array}{l}151 \\
147\end{array}$ & Imaging and therapy & {$[95]$} \\
\hline CD-CS-T7-CD-CS-polyGION-miRNA & 34 & Theranostic & [86] \\
\hline GNP-PP-polyl:C & 13 & Delivery-treatment & {$[17]$} \\
\hline GNR-CDI33 antibody & $10 \times 40 \mathrm{~nm}$ & Treatment & {$[92]$} \\
\hline GNP-Cis & 7 & Treatment & [90] \\
\hline
\end{tabular}

Abbreviations: FAL, Phe-Ala-Leu-Gly-Glu-Ala; PLGA, poly-lactic-co-glycolic acid; CTX, chlorotoxin; DOX, doxorubicin; An, angiopep-2; AK, Ala-Ala-Asn-Cys-Lys; CABT, 2-cyano-6-aminobenzothiazole; PENP, polyethyleneimine; PP, methoxypolyethylene glycol-polyethyleneimine; polyl:C, polyinosinic-polycytidylic acid; Cis, cisplatin; CD-CST7-CD-CS-polyGION-miRNA, gold iron oxide nanostars loaded with miR-100 and antimiR-2I and T7 peptide functionalized $\beta$-cyclodextrin-chitosan.

different sizes, shapes, and functionalization should be evaluated to study and determine the differential radiosensitizing efficacies.

GNPs with sizes ranging from 10 to $30 \mathrm{~nm}$, and modified with mRNAs ${ }^{80,86}$ and polymers ${ }^{17}$ have also shown beneficial effects on GBM. Ruan et al have reported three systems based on $40 \mathrm{~nm}$ GNPs that improved the median survival time of $\mathrm{C} 6$ glioma-bearing mice. ${ }^{87-89}$ Interestingly, the authors proposed a nanoparticle aggregation strategy based on GNPs modified with Ala-Ala-Asn-Cys-Lys (GNPs-AK) and 2-cyano-6-amino-benzothiazole (GNPs-CABT): GNPsAK could be hydrolyzed in the presence of legumain, producing a cycloaddition with the cyano group on GNPs-CABT. Results indicated that the aggregated nanosystem blocked exocytosis of GNPs, which led to enhanced retention in vivo and reduced systemic toxicity of doxorubicin (DOX) ${ }^{88}$ The same group improved the chemotherapeutic effect of DOX by incorporating the R8-RGD peptide (Figure $5 \mathrm{Aa}),{ }^{89}$ in which the R8 portion improves cell penetration, and the RGD sequence allows the targeting of tumor cells. In vivo results showed that GNPs functionalized with the R8RGD peptide were efficiently delivered to GBM (Figure $5 \mathrm{Ab}$ ), improving DOX's chemotherapeutic effect (Figure 5Ac).${ }^{89}$ Coluccia et al used GNPs conjugated with cisplatin combined with MR-guided FU to intensify GBM treatment. MRgFUS led to increased BBB permeability of GNPs, allowing a significant reduction of tumor growth. ${ }^{90}$ The animals did not show any neurological or behavioral sequelae from MRgFUS treatment, and the histology of organs showed no morphological alterations after a total administration of $7.5 \mathrm{mg} / \mathrm{kg}$ GNP-UP-Cis over 8 days.

Furthermore, GNPs may be used for photothermal therapy, and these studies have demonstrated a significant improvement in animal survival. ${ }^{91}$ Casanova-Carvajal et al used GNRs 
A

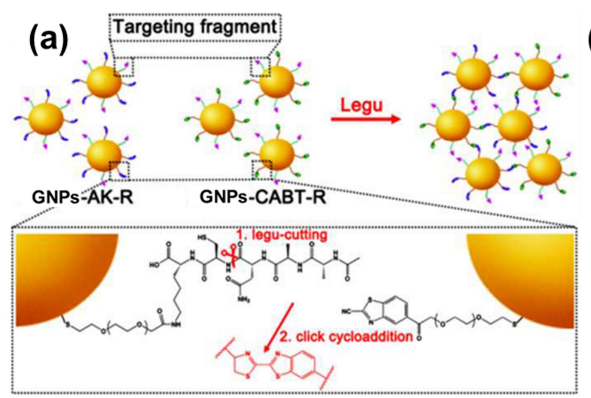

(b)

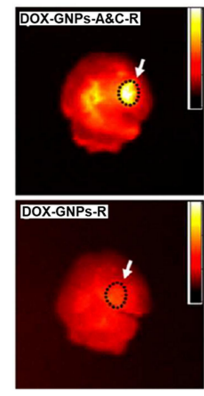

B

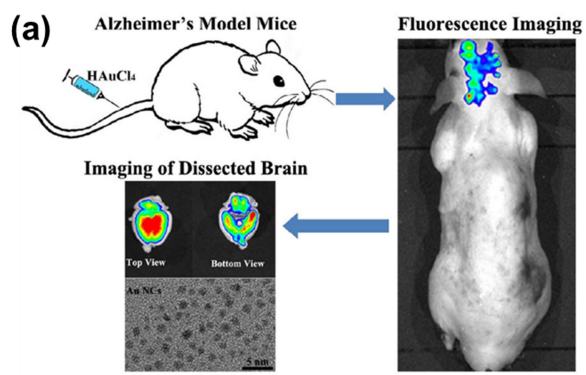

(b)

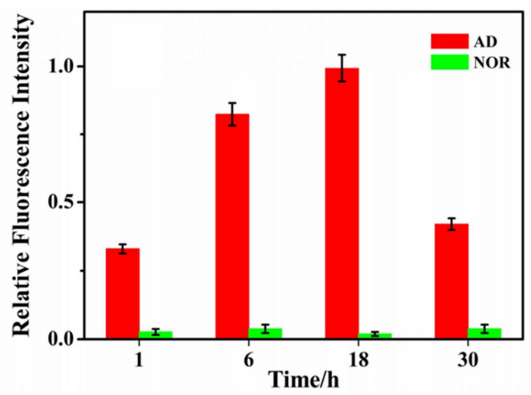

Figure 5 Applications of GNPs to brain diseases. (A) Targeting and retention of GNPs for enhanced treatment of glioblastoma. (a) Mechanism of legumain-activated click cycloaddition and aggregation process of GNPs-A\&C-R. (b) Ex vivo imaging of the brain extracted from GBM-bearing mice treated with different formulations for 24 h. (c) Left: Kaplan-Meier plots of the survival in C6 GBM-bearing mice treated with different formulations. Right: H\&E staining of GBM-bearing brain sections. The dotted region represents GBM cells, and bars represent $200 \mu \mathrm{m}$. Image A (a, b and c) adapted with permission from Ruan S, Xiao W, Hu C, Zhang H. Ligand-mediated andenzyme-directed precise targeting and retention for the enhancedtreatment of glioblastoma. ACS Appl Mat Interfaces. 2017;9 990(24):20348-20360. Copyright 20I7, American Chemical Society. ${ }^{88}$ (B) Fluorescent GNCs for in vivo imaging of AD. (a) Schematic illustration of fluorescence bio-marking of mouse brain with AD, which could be readily visualized by labeling the affected brain regions through intravenous injection of aqueous $\mathrm{HAuCl}_{4}$ solutions. (b) The variations of mean fluorescence intensity in the $\mathrm{AD}$ mouse model and the normal control group (NOR) at various time points. Image B (a and b) adapted with permission from Royal Society of Chemistry Royal Society of Chemistry, Lai L, Zhao C, Li X, et al. Fluorescent gold nanoclusters forin vivo target imaging of Alzheimer's disease. RSC Adv.2016;6:3008I-30088, permission conveyed through Copyright Clearance Center, Inc. ${ }^{95}$

Abbreviations: A\&C, AK peptide and 2-cyano-6-aminobenzothiazole (CABT); R, R8-RGD dual peptide; P, PEG; DOX, doxorubicin; N.S., Saline group.

biofunctionalized with the CD133 antibody to treat mice with glioma. This treatment produced a notable deceleration in tumor size, compared to the untreated control groups. ${ }^{92}$

With respect to glioma diagnosis, GNPs-PEG of $60 \mathrm{~nm}$ modified with the Phe-Ala-Leu-Gly-Glu-Ala peptide have been used to demarcate tumor margins with pre-operative MRI; in this study, a higher distribution of nanoparticles was observed in glioma and in the invasive margin. ${ }^{93}$ Tumors have also been visualized by using $100 \mathrm{~nm} \mathrm{GNPs}^{94}$ encapsulated in a silica layer and functionalized with PEG, and $150 \mathrm{~nm}$ GNPs radiolabeled with chlorotoxin and polyethyleneimine. ${ }^{95}$

\section{Silver and Gold Nanoparticles for Neurodegenerative and Other Brain Diseases}

Nanoparticles have also been studied as potential tools for treating and diagnosing neurodegenerative diseases, ${ }^{26,97}$ such as Alzheimer's disease (AD), ischemic stroke, ${ }^{98,99}$ prion disease, ${ }^{101}$ perinatal asphyxia, ${ }^{100}$ and herpesassociated amyloid- $\beta$ secretion. ${ }^{102}$
Neuronal death in $\mathrm{AD}$ is triggered by protein aggregates composed of the $A \beta_{1-42}$ peptide, its main therapeutic target. The use of nanosystems, which allow $A \beta$ disaggregation or destruction, has emerged as a possible treatment for $\mathrm{AD}{ }^{21,77,103,105}$ Morales-Zavala et al demonstrated that gold nanorods functionalized with the D1 peptide -which specifically recognizes the $A \beta$ peptide- decreased in vivo toxicity of $A \beta$ in the C. elegans model of AD. ${ }^{104}$ Moreover, a study in the mouse AD model that used IV injection of $50 \mathrm{~nm}$ GNPs functionalized with anthocyanins proved a reduction of neuroinflammation and neurodegeneration induced by $\mathrm{A} \beta_{1-42 .}{ }^{106}$ Lai et al developed in-situ gold nanoclusters (GNCs) of $3.3 \mathrm{~nm}$ for in vivo fluorescence imaging after IV injection of $\mathrm{HAuCl}_{4}$ solution (Figure 5Ba). Since the redox environment of the $\mathrm{AD}$ brain is completely different from that of the normal brain, under these conditions $\mathrm{HAuCl}_{4}$ forms $\mathrm{Au}$ salts, which subsequently selfassemble to form GNCs. While the presence of GNCs was confirmed in the brains of mice with $\mathrm{AD}$, no GNCs were found in the brains of normal mice (Figure 5Bb). 


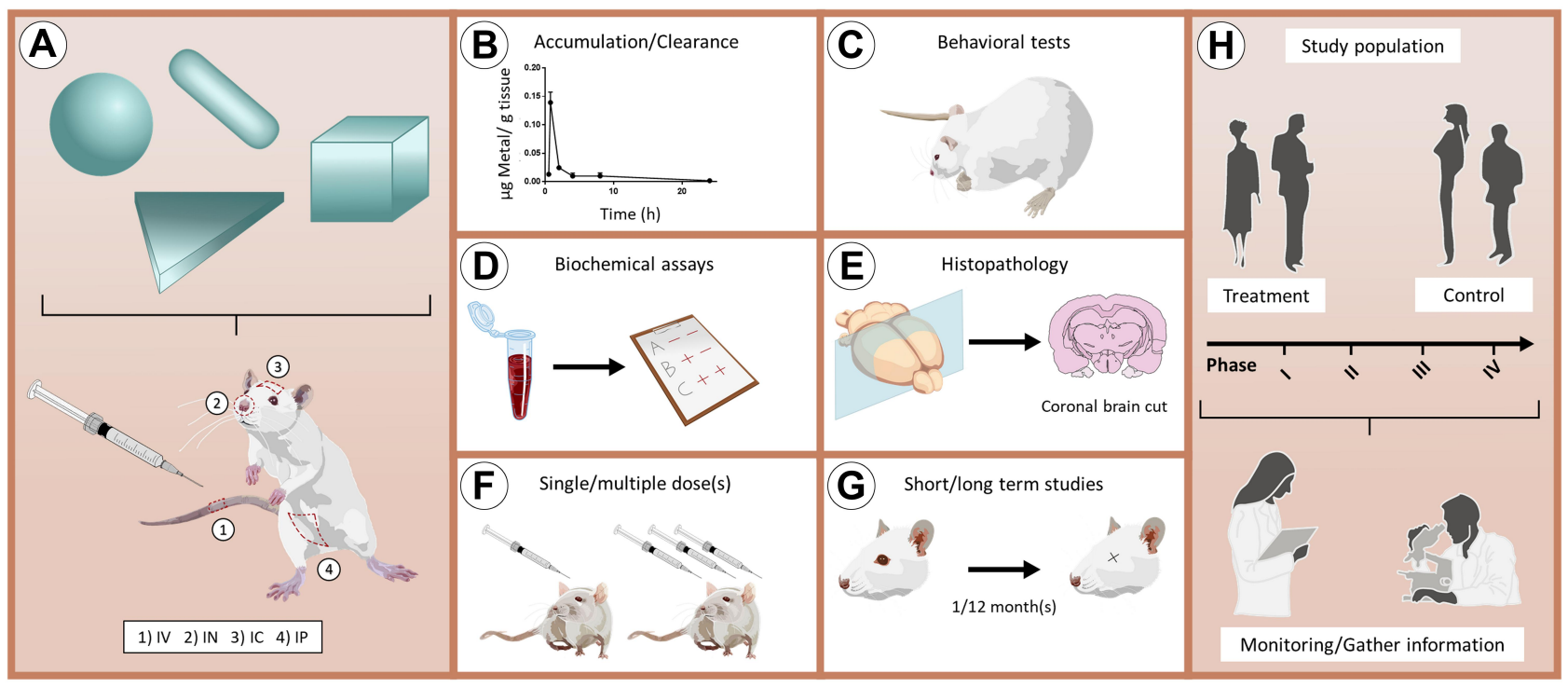

Figure 6 Ideal methodology to assess the toxicity of GNPs/SNPs for applications in brain-related disorders. (A) Schematic representation of in vivo administration of nanoparticles with different shapes through the main routes of administration. (B-G) Main in vivo experiments that can be performed to obtain a complete toxicological profile of nanoparticles. (H) Representation of a clinical trial that includes treatment and control groups. During the different phases of the clinical trials (I-IV), it is relevant to monitor individuals to gather essential information.

Abbreviations: IV, intravenous; IN, intranasal; IC, intracranial; IP, intraperitoneal.

After 4 6 weeks, neither AD nor normal mice showed histopathological abnormalities nor changes in their physical behavior. $^{96}$ In the case of SNPs, Zhang et al reported that IP administration of $12 \mathrm{~nm}$ SNPs obtained by green synthesis produced positive effects in preventing and reducing deficits in recognition and spatial memory in a rat model of sporadic AD. ${ }^{107}$ However, the toxicity of the nanoparticles used in this study and their effect was not described.

\section{Conclusions and Perspectives}

SNPs and GNPs have provided endless opportunities for in vivo biomedical applications. However, like other xenobiotics, they are usually redistributed and accumulated in some vital organs and produce toxic effects, a crucial issue to consider for potentially advancing clinical trial designs. In the case of SNPs, a limited number of in vivo toxicity studies related to neurodegenerative and other brainrelated diseases were found, probably due to their potential and major toxicity, especially in the case of bare SNPs, compared to GNPs. Currently, there is a consensus that the toxicity of SNPs is associated with the release of silver ions, which trigger biochemical alterations, abnormalities in behavior, and neurotoxic effects. As discussed previously, although in vivo functionalization of SNPs clearly diminishes their toxicity and SNPs exhibit a more powerful radiosensitizing ability than GNPs, long-term accumulation in the brain might be counterproductive.

In contrast, a clear tendency for the use of GNPs has been observed during the last decade. While it is difficult to define a correlation between size and toxicity for small GNPs ranging from 2 to $10 \mathrm{~nm}$, it was clear that larger GNPs (from 5 to $100 \mathrm{~nm}$ ), are less toxic. Moreover, functionalization of the GNP surface increases biocompatibility, facilitates crossing the BBB, and enhances delivery to the brain, improving potential treatments and diagnostic methods. Moreover, all the studies that were reviewed showed minimal or no abnormality in animal behavior after administering GNP-based nanosystems. Therefore, GNPs are definitely less toxic than SNPs.

It is important to note that clinical trials lacked complete in vivo toxicity studies, and that most of the studies with SNPs and GNPs used spherical nanoparticles. It is well known that anisotropic shapes, such as rods, stars, and prisms, have interesting physicochemical properties; for example, plasmons centered at the near-infrared region can be exploited for biomedical research and clinical applications. In the coming years, more studies should thoroughly evaluate the in vivo toxicity of these nanosystems. As an approach, 3D human CNS in vitro models can be used as a perspective, especially when using human neural precursor cells (NPCs) derived from human-induced pluripotent stem cells (hiPSCs). ${ }^{108}$ Depending on the developed 3D model, it 
is possible to mimic specific aspects of human brain physiology, including the development of brain-related disease models. These 3D models could accelerate data acquisition related to SNP and GNP neurotoxicity, allow the development of high throughput screening methodologies, and reduce the time-consuming animal experimentation.

Figure 6 illustrates the main toxicity studies that should be performed to obtain a complete toxicological profile of SNPand GNP-based nanosystems. The use of in vivo experiments, such as accumulation/clearance studies, behavioral tests, biochemical assays, histopathology examination, administration of single/multiple doses and short/long term studies will allow many of the interesting studies described in this review to get closer to the next step: clinical research. We hope that this review will stimulate further development of SNPs and GNPs of different sizes and shapes, and we encourage the scientific community to continue with in vivo experimentation, especially regarding the CNS and brain-related diseases.

\section{Acknowledgments}

D.F.B. would like to thank Fondecyt grant 11200416, E.G. T thanks an ANID PhD fellowship (21151400), and M.P.O thanks Fondecyt Postdoctorate Project 3180651. We also would like to thank Fondecyt grants 1190623 (to E.A) and 1170929 (to M.J.K). All authors would like to thank Fondap grant 15130011.

\section{Disclosure}

The authors report no conflicts of interest in this study.

\section{References}

1. Elahi N, Kamali M, Baghersad MH. Recent biomedical applications of gold nanoparticles: a review. Talanta. 2018;184:537-556. doi:10.1016/ j.talanta.2018.02.088

2. Carneiro P, Morais S, Pereira MC. Nanomaterials towards biosensing of alzheimer's disease biomarkers. Nanomaterials. 2019;9(12):1663. doi:10.3390/nano9121663

3. Yeh Y-C, Creran B, Rotello VM. Gold nanoparticles: preparation, properties, and applications in bionanotechnology. Nanoscale. 2012;4 (6):1871-1880. doi:10.1039/c1nr11188d

4. Willets KA, Van Duyne RP. Localized surface plasmon resonance spectroscopy and sensing. Ann Rev Phys Chem. 2007;58(1):267-297. doi:10.1146/annurev.physchem.58.032806.104607

5. Azzazy HME, Mansour MMH. In vitro diagnostic prospects of nanoparticles. Clinica Chimica Acta. 2009;403(1-2):1-8. doi:10.1016/j.cca.2009.01.016

6. Naz F, Koul V, Srivastava A, Gupta YK, Dinda AK. Biokinetics of ultrafine gold nanoparticles (AuNPs) relating to redistribution and urinary excretion: a long-term in vivo study. J Drug Target. 2016;24 (8):720-729. doi:10.3109/1061186X.2016.1144758

7. Betzer O, Shilo M, Opochinsky R, et al. The effect of nanoparticle size on the ability to cross the blood-brain barrier: an in vivo study. Nanomedicine. 2017;12(13):1533-1546. doi:10.2217/nnm-2017-0022
8. Liu P, Huang Z, Chen Z, et al. Silver nanoparticles: a novel radiation sensitizer for glioma? Nanoscale. 2013;5(23):11829. doi:10.1039/c3nr01351k

9. Nakkala JR, Mata R, Raja K, Khub Chandra V, Sadras SR. Green synthesized silver nanoparticles: catalytic dye degradation, in vitro anticancer activity and in vivo toxicity in rats. Mat Sci Eng C. 2018;91:372-381. doi:10.1016/j.msec.2018.05.048

10. Khan I, Bahuguna A, Krishnan M, et al. The effect of biogenic manufactured silver nanoparticles on human endothelial cells and zebrafish model. Sci Total Environ. 2019;679:365-377. doi:10.1016/j.scitotenv.2019.05.045

11. Hinman JG, Stork AJ, Varnell JA, Gewirth AA, Murphy CJ. Seed mediated growth of gold nanorods: towards nanorod matryoshkas. Faraday Discuss. 2016;191:9-33. doi:10.1039/ C6FD00145A

12. Ali MRK, Wu Y, El-Sayed MA. Gold-nanoparticle-assisted plasmonic photothermal therapy advances toward clinical application. $J$ Phys Chem C. 2019;123(25):15375-15393. doi:10.1021/acs.jpcc.9b01961

13. Huang X, El-Sayed MA. Plasmonic photo-thermal therapy (PPTT). Alexandria J Med. 2011;47(1):1-9. doi:10.1016/j. ajme.2011.01.001

14. Korani M, Ghazizadeh E, Korani S, Hami Z, MohammadiBardbori A. Effects of silver nanoparticles on human health. Eur J Nanomed. 2015;7(1):51-62. doi:10.1515/ejnm-2014-0032

15. Yu -K-K, Li K, Qin -H-H, et al. Construction of $\mathrm{pH}$-sensitive "submarine" based on gold nanoparticles with double insurance for intracellular $\mathrm{pH}$ mapping, quantifying of whole cells and in vivo applications. ACS Appl Mat Interfaces. 2016;8 (35):22839-22848. doi:10.1021/acsami.6b06331

16. Zhou W, Gao X, Liu D, Chen X. Gold nanoparticles for in vitro diagnostics. Chem Rev. 2015;115(19):10575-10636. doi:10.1021/ acs.chemrev.5b00100

17. Yin $\mathrm{P}, \mathrm{Li} \mathrm{H}, \mathrm{Ke} \mathrm{C}$, et al. Intranasal delivery of immunotherapeutic nanoformulations for treatment of glioma through in situ activation of immune response. Int J Nanomed. 2020;15:1499-1515. doi:10.2147/IJN.S240551

18. Singh P, Pandit S, Mokkapati VRSS, Garg A, Ravikumar V, Mijakovic I. Gold nanoparticles in diagnostics and therapeutics for human cancer. Int J Mol Sci. 2018;19(7):1979. doi:10.3390/ ijms19071979

19. Shilo M, Motiei M, Hana P, Popovtzer R. Transport of nanoparticles through the blood-brain barrier for imaging and therapeutic applications. Nanoscale. 2014;6(4):2146-2152. doi:10.1039/ C3NR04878K

20. Lee U, Yoo C-J, Kim Y-J, Yoo Y-M. Cytotoxicity of gold nanoparticles in human neural precursor cells and rat cerebral cortex. $J$ Biosci Bioeng. 2016;121(3):341-344. doi:10.1016/j.jbiosc.2015.07.004

21. Velasco-aguirre C, Morales-zavala F, Salas-Huenuleo E, GallardoToledo E, Andonie O. Improving gold nanorod delivery to the central nervous system by conjugation to the shuttle Angiopep-2. Nanomedicine. 2017;12(20):2503-2517. doi:10.2217/nnm-20170181

22. Ahlberg S, Antonopulos A, Diendorf J, et al. PVP-coated, negatively charged silver nanoparticles: a multi-center study of their physicochemical characteristics, cell culture and in vivo experiments. Beilstein J Nanotechnol. 2014;5:1944-1965. doi:10.3762/bjnano.5.205

23. Repar N, Li H, Aguilar JS, Li QQ, Drobne D, Hong Y. Silver nanoparticles induce neurotoxicity in a human embryonic stem cell-derived neuron and astrocyte network. Nanotoxicology. 2018;12(2):104-116. doi:10.1080/17435390.2018.1425497

24. Hadrup N, Loeschner K, Mortensen A, et al. The similar neurotoxic effects of nanoparticulate and ionic silver in vivo and in vitro. Neurotoxicology. 2012;33(3):416-423. doi:10.1016/j. neuro.2012.04.008 
25. Al-Doaiss AA, Jarrar Q, Alshehri M, Jarrar B. In vivo study of silver nanomaterials' toxicity with respect to size. Toxicol Indust Health. 2020;36(8):540-557. doi:10.1177/0748233720937201

26. Jo DH, Kim JH, Lee TG, Kim JH. Size, surface charge, and shape determine therapeutic effects of nanoparticles on brain and retinal diseases. Nanomed Nanotechnol Biol Med. 2015;11 (7):1603-1611. doi:10.1016/j.nano.2015.04.015

27. Antsiferova A, Buzulukov Y, Demin V, Kashkarov P, Kovalchuk M, Petritskaya E. Extremely low level of Ag nanoparticle excretion from mice brain in in vivo experiments. IOP Conference Series. 2015;98:012003. doi:10.1088/1757-899X/98/ $1 / 012003$

28. Chrastina A, Schnitzer JE. Iodine-125 radiolabeling of silver nanoparticles for in vivo SPECT imaging. International Journal of Nanomedicine. 2010;5:653. doi:10.2147/IJN.S11677

29. Zhu J, Chin J, Wängler C, Wängler RB, Lennox R, Schirrmacher R. Rapid 18F-labeling and loading of PEGylated gold nanoparticles for in vivo applications. Bioconjugate Chemistry. 2014;25(6):1143-1150. doi:10.1021/bc5001593

30. Dos Santos VE, Filho AV, Ribeiro Targino AG, et al. A new "Silver-Bullet" to treat caries in children - nano silver fluoride: a randomised clinical trial. $J$ Dentist. 2014;42(8):945-951. doi:10.1016/j.jdent.2014.05.017

31. Tirupathi S, Nirmala SV, Rajasekhar S, et al. Comparative cariostatic efficacy of a novel Nano-silver fluoride varnish with $38 \%$ silver diamine fluoride varnish a double-blind randomized clinical trial. J Clin Exp Dentist. 2019;11:e105-e112. doi:10.4317/ jced. 54995

32. Odatsu T, Kuroshima S, Sato M, et al. Antibacterial properties of nano-Ag coating on healing abutment: an in vitro and clinical study. Antibiotics. 2020;9(6):347. doi:10.3390/antibiotics9060347

33. Chai S-H, Wang Y, Qiao Y, et al. Bio fabrication of silver nanoparticles as an effective wound healing agent in the wound care after anorectal surgery. $J$ Photochem Photobiol $B$ 2018;178:457-462. doi:10.1016/j.jphotobiol.2017.10.024

34. Libutti SK, Paciotti GF, Byrnes AA, et al. Phase I and pharmacokinetic studies of CYT-6091, a novel PEGylated colloidal gold-rhTNF nanomedicine. Clin Cancer Res. 2010;16 (24):6139-6149. doi:10.1158/1078-0432.CCR-10-0978

35. Anselmo AC, Mitragotri S. Nanoparticles in the clinic. Bioeng Translat Med. 2016;1(1):10-29. doi:10.1002/btm2.10003

36. Kumthekar P, Rademaker A, Ko C, et al. A Phase 0 first-inhuman study using NU-0129: a gold base spherical nucleic acid (SNA) nanoconjugate targeting BCL2L12 in recurrent glioblastoma patients. J Clin Oncol. 2019;37(15_suppl):3012. doi:10.1200/JCO.2019.37.15_suppl.3012

37. Rastinehad AR, Anastos H, Wajswol E, et al. Gold nanoshell-localized photothermal ablation of prostate tumors in a clinical pilot device study. Proc Nat Acad Sci. 2019;116 (37):18590-18596. doi:10.1073/pnas.1906929116

38. Khoobchandani M, Katti KK, Karikachery AR, et al. New approaches in breast cancer therapy through green nanotechnology and nano-ayurvedic medicine - pre-clinical and pilot human clinical investigations. Int $J$ Nanomed. 2020;15:181-197. doi:10.2147/IJN.S219042

39. Amal H, Leja M, Funka K, et al. Detection of precancerous gastric lesions and gastric cancer through exhaled breath. Gut 2016;65(3):400-407. doi:10.1136/gutjnl-2014-308536

40. Kharlamov AN, Tyurnina AE, Veselova VS, Kovtun OP, Shur VY, Gabinsky JL. Silica-gold nanoparticles for atheroprotective management of plaques: results of the NANOM-FIM trial. Nanoscale. 2015;7(17):8003-8015. doi:10.1039/c5nr01050k

41. Lau E, Kaminsky SC, \& Humbert M. (2015). Detection of exhaled breath olfactory signature of pah with artificial nose: From proof-of-concept to clinical validation. Revue des Maladies Respiratoires, 32, A253. doi:10.1016/j.rmr.2014.10.717
42. Sawicki K, Czajka M, Matysiak-Kucharek M, et al. Toxicity of metallic nanoparticles in the central nervous system. Nanotechnol Rev. 2019;8:175-200. doi:10.1515/ntrev-2019-0017

43. Ferdous Z, Nemmar A. Health impact of silver nanoparticles: a review of the biodistribution and toxicity following various routes of exposure. Int J Mol Sci. 2020;21(7):2375. doi:10.3390/ ijms 21072375

44. Hadrup N, Lam HR. Oral toxicity of silver ions, silver nanoparticles and colloidal silver - a review. Regulat Toxicol Pharmacol. 2014;68(1):1-7. doi:10.1016/j.yrtph.2013.11.002

45. Nel A. Toxic potential of materials at the nanolevel. Science (80-). 2006;311(5761):622-627. doi:10.1126/science.1114397

46. Dąbrowska-Bouta B, Zięba M, Orzelska-Górka J, et al. Influence of a low dose of silver nanoparticles on cerebral myelin and behavior of adult rats. Toxicology. 2016;363-364:29-36. doi:10.1016/j.tox.2016.07.007

47. Powers CM, Wrench N, Ryde IT, et al. Silver impairs neurodevelopment: studies in PC12 cells. Env Health Perspect. 2010;118 (1):73-79. doi:10.1289/ehp.0901149

48. Powers CM, Badireddy AR, Ryde IT, et al. Silver nanoparticles compromise neurodevelopment in PC12 cells: critical contributions of silver ion, particle size, coating, and composition. Env Health Perspect. 2011;119(1):37-44. doi:10.1289/ehp.1002337

49. Wang J, Rahman MF, Duhart HM, et al. Expression changes of dopaminergic system-related genes in PC12 cells induced by manganese, silver, or copper nanoparticles. Neurotoxicology. 2009;30(6):926-933. doi:10.1016/j.neuro.2009.09.005

50. Soria C, Coccini T, De Simone U, et al. Enhanced toxicity of silver nanoparticles in transgenic Caenorhabditis elegans expressing amyloidogenic proteins. Amyloid. 2015;22(4):221-228. doi:10.3109/13506129.2015.1077216

51. Wen R, Yang X, Hu L, Sun C, Zhou Q, Jiang G. Brain-targeted distribution and high retention of silver by chronic intranasal instillation of silver nanoparticles and ions in Sprague-Dawley rats. J Appl Toxicol. 2016;36(3):445-453. doi:10.1002/jat.3260

52. van der Zande M, Vandebriel RJ, Van Doren E, et al. Distribution, elimination, and toxicity of silver nanoparticles and silver ions in rats after 28-day oral exposure. ACS Nano. 2012;6(8):7427-7442. doi:10.1021/nn302649p

53. Zhang X-F, Shen W, Gurunathan S. Silver nanoparticle-mediated cellular responses in various cell lines: an in vitro model. Int J Mol Sci. 2016;17(10):1-26. doi:10.3390/ijms17101603

54. Lee Y-H, Cheng F-Y, Chiu H-W, et al. Cytotoxicity, oxidative stress, apoptosis and the autophagic effects of silver nanoparticles in mouse embryonic fibroblasts. Biomaterials. 2014;35 (16):4706-4715. doi:10.1016/j.biomaterials.2014.02.021

55. Huang C-L, Hsiao I-L, Lin H-C, Wang C-F, Huang Y-J, Chuang C-Y. Silver nanoparticles affect on gene expression of inflammatory and neurodegenerative responses in mouse brain neural cells. Env Res. 2015;136:253-263. doi:10.1016/j. envres.2014.11.006

56. Strużyńska L. The application, neurotoxicity, and related mechanisms of silver nanoparticles. In: Neurotoxicity of Nanomaterials and Nanomedicine. Academic Press; 2017:151-177.

57. Rocha A, Zhou Y, Kundu S, González JM, Bradleighvinson S, Liang H. In vivo observation of gold nanoparticles in the central nervous system of Blaberus discoidalis. J Nanobiotechnology. 2011;9(1):5. doi:10.1186/1477-3155-9-5

58. Pannerselvam B, Devanathadesikan V, Alagumuthu TS, Kanth V, Thangavelu KP. Assessment of in-vivo biocompatibility evaluation of phytogenic gold nanoparticles on Wistar albino male rats. IET Nanobiotechnol. 2020;14(4):314-324. doi:10.1049/iet-nbt.2019.0116

59. Lasagna-Reeves C, Gonzalez-Romero D, Barria MA, et al. Bioaccumulation and toxicity of gold nanoparticles after repeated administration in mice. Biochem Biophys Res Commun. 2010;393 (4):649-655. doi:10.1016/j.bbrc.2010.02.046 
60. Li C-H, Shyu M-K, Jhan C, et al. Gold nanoparticles increase endothelial paracellular permeability by altering components of endothelial tight junctions, and increase blood-brain barrier permeability in mice. Toxicol Sci. 2015;148(1):192-203. doi:10.1093/toxsci/kfv176

61. Spinelli A, Girelli M, Arosio D, et al. Intracisternal delivery of PEG-coated gold nanoparticles results in high brain penetrance and long-lasting stability. $J$ Nanobiotechnol. 2019;17:1-13. doi:10.1186/s12951-019-0481-3

62. Sousa F, Mandal S, Garrovo C, et al. Functionalized gold nanoparticles: a detailed in vivo multimodal microscopic brain distribution study. Nanoscale. 2010;2(12):2826-2834. doi:10.1039/ c0nr00345j

63. Ye D, Zhang X, Yue Y, et al. Focused ultrasound combined with microbubble-mediated intranasal delivery of gold nanoclusters to the brain. J Control Release. 2018;286:145-153. doi:10.1016/j. jconrel.2018.07.020

64. Guerrero S, Herance JR, Rojas S, et al. Synthesis and in vivo evaluation of the biodistribution of a 18 F-labeled conjugate gold-nanoparticle-peptide with potential biomedical application. Bioconjugate Chem. 2012;23(3):399-408. doi:10.1021/bc200362a

65. Hutter E, Boridy S, Labrecque S, et al. Microglial response to gold nanoparticles. ACS Nano. 2010;4(5):2595-2606. doi:10.1021/nn901869f

66. Saraiva C, Praça C, Ferreira R, Santos T, Ferreira L, Bernardino L. Nanoparticle-mediated brain drug delivery: overcoming bloodbrain barrier to treat neurodegenerative diseases. $J$ Control Release. 2016;235:34 47. doi:10.1016/j.jconrel.2016.05.044

67. Clark AJ, Davis ME. Increased brain uptake of targeted nanoparticles by adding an acid-cleavable linkage between transferrin and the nanoparticle core. Proc Nat Acad Sci. 2015;112 (40):12486-12491. doi:10.1073/pnas. 1517048112

68. Nair LV, Nair RV, Shenoy SJ, Thekkuveettil A, Jayasree RS. Blood brain barrier permeable gold nanocluster for targeted brain imaging and therapy: an in vitro and in vivo study. $J$ Mat Chem B. 2017;5(42):8314-8321. doi:10.1039/C7TB02247F

69. Arranz-Gibert P, Prades R, Guixer B, et al. HAI peptide and backbone analogs - validation and enhancement of biostability and bioactivity of BBB shuttles. Sci Rep. 2018;8(1):17932. doi:10.1038/s41598-018-35938-8

70. Khademi S, Sarkar S, Shakeri-Zadeh A, et al. Targeted gold nanoparticles enable molecular CT imaging of head and neck cancer: an in vivo study. Int $J$ Biochem Cell Biol. 2019;114:105554. doi:10.1016/j.biocel.2019.06.002

71. Chan TG, Morse SV, Copping MJ, Choi J, Vilar R. Targeted delivery of DNA-Au nanoparticles across the blood-brain barrier using focused ultrasound. ChemMedChem. 2018;13 (13):1311-1314. doi:10.1002/cmdc.201800262

72. Sultan D, Ye D, Heo GS, et al. Focused ultrasound enabled trans-blood brain barrier delivery of gold nanoclusters: effect of surface charges and quantification using positron emission tomography. Small. 2018;14(30):1-9. doi:10.1002/smll.201703115

73. Dhuria SV, Hanson LR, FreyWH II. Intranasal delivery to the central nervous system: mechanisms and experimental considerations. J Pharm Sci. 2010;99(4):1654-1673. doi:10.1002/ jps.21924

74. Betzer O, Perets N, Angel A, et al. In vivo neuroimaging of exosomes using gold nanoparticles. ACS Nano. 2017;11 (11):10883-10893. doi:10.1021/acsnano.7b04495

75. Salem HF, Kharshoum RM, Abou-Taleb HA, Naguib DM. Brain targeting of resveratrol through intranasal lipid vesicles labelled with gold nanoparticles: in vivo evaluation and bioaccumulation investigation using computed tomography and histopathological examination. $J$ Drug Target. 2019;27(10):1127-1134. doi:10.1080/1061186X.2019.1608553
76. Ye D., Luan J, Pang H, Yang Y, Nazeri A, Rubin JB, Chen H. Characterization of focused ultrasound-mediated brainstem delivery of intranasally administered agents. Journal of Controlled Release. 2020;328:276-285. doi:10.1016/j.jconrel.2020.08.053

77. Gallardo-Toledo E, Tapia-Arellano A, Celis F, et al. Intranasal administration of gold nanoparticles designed to target the central nervous system: fabrication and comparison between nanospheres and nanoprisms. Int J Pharma. 2020;590:119957. doi:10.1016/j. ijpharm.2020.119957

78. Pinel S, Thomas N, Boura C, Barberi-heyob M. Approaches to physical stimulation of metallic nanoparticles for glioblastoma treatment. Adv Drug Deliv Rev. 2019;138:344-357. doi:10.1016/ j.addr.2018.10.013

79. Nicolson F, Andreiuk B, Andreou C, Hsu H, Rudder S, Kircher MF. Non-invasive in vivo imaging of cancer using surface-enhanced spatially offset raman spectroscopy (SESORS). Theranostics. 2019;9(20):5899-5913. doi:10.7150/ thno.36321

80. Kouri FM, Hurley LA, Daniel WL, Day E. miR-182 integrates apoptosis, growth, and differentiation programs in glioblastoma. Genes Dev. 2015;29(7):732-745. doi:10.1101/gad.257394.114

81. Bobyk L, Edouard M, Deman P, et al. Photoactivation of gold nanoparticles for glioma treatment. Nanomed Nanotechnol Biol Med. 2013;9(7):1089-1097. doi:10.1016/j.nano.2013.04.007

82. Tamborini M, Locatelli E, Rasile M, et al. A combined approach employing chlorotoxin-nanovectors and low dose radiation to reach infiltrating tumor niches in glioblastoma. ACS Nano. 2016;10(2):2509-2520. doi:10.1021/acsnano.5b07375

83. Liu PD, Jin H, Guo Z, et al. Silver nanoparticles outperform gold nanoparticles in radiosensitizing U251 cells in vitro and in an intracranial mouse model of glioma. Int $J$ Nanomed. 2016;11:5003-5014. doi:10.2147/IJN.S115473

84. Meidanchi A, Akhavan O, Khoei S, Shokri AA, Hajikarimi Z, Khansari N. ZnFe2O4 nanoparticles as radiosensitizers in radiotherapy of human prostate cancer cells. Mat Sci Eng C. 2015;46:394-399. doi:10.1016/j.msec.2014.10.062

85. Liu J, Liang Y, Liu T, Li D, Yang X. Anti-EGFR-conjugated hollow gold nanospheres enhance radiocytotoxic targeting of cervical cancer at megavoltage radiation energies. Nanoscale Res Lett. 2015;10(1):218. doi:10.1186/s11671-015-0923-2

86. Sukumar UK, Bose RJC, Malhotra M, et al. Intranasal delivery of targeted polyfunctional gold-iron oxide nanoparticles loaded with therapeutic microRNAs for combined theranostic multimodality imaging and presensitization of glioblastoma to temozolomide. Biomaterials. 2019;218:119342. doi:10.1016/j.biomaterials.2019.119342

87. Ruan S, Yuan M, Zhang L, et al. Tumor microenvironment sensitive doxorubicin delivery and release to glioma using angiopep-2 decorated gold nanoparticles. Biomaterials. 2015;37:425-435. doi:10.1016/j.biomaterials.2014.10.007

88. Ruan S, Hu C, Tang X, et al. Increased gold nanoparticle retention in brain tumors by in situ enzyme-induced aggregation. $A C S$ Nano. 2016;10(11):10086-10098. doi:10.1021/acsnano.6b05070

89. Ruan S, Xiao W, Hu C, Zhang H. Ligand-mediated and enzyme-directed precise targeting and retention for the enhanced treatment of glioblastoma. ACS Appl Mat Interfaces. 2017;9 (24):20348-20360. doi:10.1021/acsami.7b02303

90. Coluccia D, Figueiredo CA, Wu MYJ, et al. Enhancing glioblastoma treatment using cisplatin-gold-nanoparticle conjugates and targeted delivery with magnetic resonance-guided focused ultrasound. Nanomed Nanotechnol Biol Med. 2018;14 (4):1137-1148. doi:10.1016/j.nano.2018.01.021

91. Day ES, Thompson PA, Zhang L, et al. Nanoshell-mediated photothermal therapy improves survival in a murine glioma model. J Neuro-Oncol. 2011;104(1):55-63. doi:10.1007/s11060010-0470-8 
92. Casanova-carvajal O, Urbano-bojorge AL, Ramos M, SerranoOlmedo JJ, Martínez-Murillo R. Slowdown intracranial glioma progression by optical hyperthermia therapy: study on a CT-2A mouse astrocytoma model. Nanotechnology. 2019;30(35):355101. doi:10.1088/1361-6528/ab2164

93. Yue Q, Gao X, Yu Y, et al. An EGFRvIII targeted dual-modal gold nanoprobe for imaging-guided brain tumor surgery. Nanoscale. 2017;9(23):7930-7940. doi:10.1039/C7NR01077J

94. Neuschmelting V, Harmsen S, Beziere N, et al. Dual-modality surface-enhanced resonance raman scattering and multispectral optoacoustic tomography nanoparticle approach for brain tumor delineation. Small. 2018;14(23):1-10. doi:10.1002/ smll.201800740

95. Zhao L, Li Y, Zhu J, et al. Chlorotoxin peptide-functionalized polyethylenimine-entrapped gold nanoparticles for glioma SPECT/CT imaging and radionuclide therapy. J Nanobiotechnol. 2019;17(1):1-13. doi:10.1186/s12951-019-0462-6

96. Lai L, Zhao C, Li X, et al. Fluorescent gold nanoclusters for in vivo target imaging of Alzheimer's disease. RSC $A d v$. 2016;6:30081-30088. doi:10.1039/C6RA01027J

97. Li Y, Liu R, Ji W, Li Y, Liu L, Zhang X. Delivery systems for theranostics in neurodegenerative diseases. Nano Res. 2018;11 (10):5535-5555. doi:10.1007/s12274-018-2067-Z

98. Kim J-Y, Ryu JH, Schellingerhout D, et al. Direct imaging of cerebral thromboemboli using computed tomography and fibrin-targeted gold nanoparticles. Theranostics. 2015;5 (10):1098-1114. doi:10.7150/thno.11679

99. Yoon H-J, Lee E-S, Kang M, Jeong Y, Park J-H. In vivo multiphoton luminescence imaging of cerebral vasculature and bloodbrain barrier integrity using gold nanoparticles. $J$ Mat Chem B. 2015;3(15):2935-2938. doi:10.1039/C4TB01759E

100. Vio V, Riveros AL, Tapia-Bustos A, et al. 2018. Gold nanorods/ siRNA complex administration for knockdown of PARP-1: a potential treatment for perinatal asphyxia. International journal of nanomedicine, 13, 6839. doi:10.2147/IJN.S175076

101. Ai Tran HN, Sousa F, Moda F, et al. A novel class of potential prion drugs: preliminary in vitro and in vivo data for multilayer coated gold nanoparticles. Nanoscale. 2010;2:2724. doi:10.1039/ c0nr00551g
102. Serramia MJ, De La Mata FJ, Bullido MJ, et al. Gold nanoparticles crossing blood-brain barrier prevent HSV-1 infection and reduce herpes associated amyloid- $\beta$ secretion. $J$ Clin Med. 2020;9(1):155. doi:10.3390/jcm9010155

103. Prades R, Guerrero S, Araya E, et al. Delivery of gold nanoparticles to the brain by conjugation with a peptide that recognizes the transferrin receptor. Biomaterials. 2012;33:7194-7205. doi:10.1016/j.biomaterials.2012.06.063

104. Morales-Zavala F, Arriagada H, Hassan N, et al. 2017. Peptide multifunctionalized gold nanorods decrease toxicity of $\beta$-amyloid peptide in a Caenorhabditis elegans model of Alzheimer's disease. Nanomedicine: Nanotechnology. Biology and Medicine, 13(7), 2341-2350. doi:10.1016/j.nano.2017.06.013

105. Yin T, Xie W, Sun J, Yang L, Liu J. Penetratin peptidefunctionalized gold nanostars: enhanced BBB permeability and NIR photothermal treatment of alzheimer's disease using ultralow irradiance. ACS Appl Mater Inter. 2016;8:19291-19302. doi:10.1021/acsami.6b05089

106. Kim MJ, Rehman SU, Amin FU, Kim MO. Enhanced neuroprotection of anthocyanin-loaded PEG-gold nanoparticles against A $\beta 1$-42-induced neuroinflammation and neurodegeneration via the NF-KB/JNK/GSK3 $\beta$ signaling pathway. Nanomed Nanotechnol Biol Med. 2017;13:2533-2544. doi:10.1016/j. nano.2017.06.022

107. Zhang X, Li Y, Hu Y. Green synthesis of silver nanoparticles and their preventive effect in deficits in recognition and spatial memory in sporadic Alzheimer's rat model. Colloids Surf A Physicochem Eng Asp. 2020;605:125288. doi:10.1016/j. colsurfa.2020.125288

108. Leite PEC, Pereira MR, Harris G, et al. Suitability of 3D human brain spheroid models to distinguish toxic effects of gold and poly-lactic acid nanoparticles to assess biocompatibility for brain drug delivery. Part Fibre Toxicol. 2019;16:1-20. doi:10.1186/ s12989-019-0307-3
International Journal of Nanomedicine

\section{Publish your work in this journal}

The International Journal of Nanomedicine is an international, peerreviewed journal focusing on the application of nanotechnology in diagnostics, therapeutics, and drug delivery systems throughout the biomedical field. This journal is indexed on PubMed Central, MedLine, CAS, SciSearch ${ }^{\circledR}$, Current Contents ${ }^{\mathbb{R}} /$ Clinical Medicine,

\section{Dovepress}

Journal Citation Reports/Science Edition, EMBase, Scopus and the Elsevier Bibliographic databases. The manuscript management system is completely online and includes a very quick and fair peer-review system, which is all easy to use. Visit http://www.dovepress.com/ testimonials.php to read real quotes from published authors. 